\title{
Practical Use of Stairs to Assess Fitness, Prescribe and Perform Physical Activity Training
}

\author{
Jasem Ramadan Al Kandari ${ }^{*}$, Salman Mohammad², Ruqayyah Al-Hashem1, \\ Girma Telahoun'1, Mario Barac-Nieto ${ }^{1}$ \\ ${ }^{1}$ Department of Physiology, Faculty of Medicine, Kuwait University, Al-Khaldiya, Kuwait \\ ${ }^{2}$ Department of Physical Education, College of Basic Education, The Public Authority of Applied Education and Training, \\ Adailiyah, Kuwait \\ Email: *ramadan@hsc.edu.kw
}

How to cite this paper: Al Kandari, J.R., Mohammad, S., Al-Hashem, R., Telahoun, G. and Barac-Nieto, M. (2016) Practical Use of Stairs to Assess Fitness, Prescribe and Perform Physical Activity Training. Health, 8, 1402-1410.

http://dx.doi.org/10.4236/health.2016.813141

Received: July 1, 2016

Accepted: October 25, 2016

Published: October 28, 2016

Copyright $\odot 2016$ by authors and Scientific Research Publishing Inc. This work is licensed under the Creative Commons Attribution International License (CC BY 4.0).

http://creativecommons.org/licenses/by/4.0/

(c) (i) Open Access

\section{Abstract}

Aim: Evaluating climbing stairs for prescription and implementation of physical activity regimes. Methods: Healthy females $(\mathrm{F}, \mathrm{n}=14)$, and males $(\mathrm{M}, \mathrm{n}=15)$ participated. By climbing 100 steps of stairs with $0.173 \mathrm{~m}$ height, Heart rate (HR) and oxygen uptake were measured throughout the floors; Blood pressure (BP) was measured at ground and the 5th floors only. Results: Energy increased from 2 to 7.6 was metabolic equivalents (METs $=3.5 \mathrm{ml} \mathrm{O} / \mathrm{min} \cdot \mathrm{kg}$ ) at $17.3 \mathrm{~m}$ elevation in $2 \mathrm{~min}$. at the 5th floor, and percent Heart Rate Reserve (\%HRR) was $66.17 \%$ in F and $48.7 \%$ in M, proportional to their aerobic efforts. Average climbing efficiency was $15.8 \pm 2.3 \%$ (n = 29). Aerobic capacity estimated dividing the highest work rate $\left(17.3 \mathrm{Kg} \cdot \mathrm{m} /{ }^{2} \mathrm{~min} \cdot \mathrm{Kg}\right.$ $\times 0.00239=0.0207 \mathrm{Kcal} / \mathrm{min} \cdot \mathrm{Kg})$, by fractional effort $(\mathrm{F}=0.6617, \mathrm{M}=0.487)$ and fractional efficiency (0.158), at $5 \mathrm{Kcal} / \mathrm{L} \mathrm{O}_{2}$ was $0.040 \mathrm{in} \mathrm{F}$ and $0.054 \mathrm{~L} \mathrm{O}_{2} / \mathrm{Kg} \cdot \mathrm{min}$ in M. Minimum training intensity reached at the 3rd floor by $F$. In $M$ the highest \%HRR reached was $48.7 \%$ at the 5th floor, insufficient for training. Conclusions: Stairs used for submaximal evaluation of aerobic capacity and for target intensity prescription. Training, levels climbed, repetitions per day (if 5, 100 Kcal per day, ascending) and number of days/week are adjusted. Full regime requires up to 7.6 METs, a total of 532 and $140 \mathrm{MET}$.min/week ascending and descending, respectively. Intensities $>7.6 \mathrm{MET}$, climbing rate should be $>8.65 \mathrm{~m} / \mathrm{min}$. Limiting ascent to 1 (3.5 METs) or 2 (5.5 METs) floors or only descents (2 - 3 METs) may be used for unfit subjects. This method is useful for those with no access to sophisticated facilities.

\section{Keywords}

Stair Climbing, Descent, Heart Rate Reserve, Aerobic Effort, Oxygen Cost, Work Output, Efficiency, Aerobic Capacity, Exercise Prescription, Training 


\section{Introduction}

The Gulf Cooperation Council Countries have very high percentages of non-communicable diseases, namely, obesity, diabetes and cardiovascular diseases [1]. The United Nations identified inactivity, one of the four main risk factors for these chronic diseases [2]. The aim of this study was to explore whether climbing stairs can be used by the family physician and other healthcare professionals for evaluation, prescription and implementation of physical activity regimes (training) in various types of patients. Purpose: To measure the physiological responses in ascending stairs for both male and female subjects, and to explore the possibility of using the stairs for exercise fitness evaluation, prescription and training.

\section{Methods}

Healthy male and female volunteers (fourteen females F, $30.9 \pm 2.86$ years of age, and fifteen males $M, 33.3 \pm 2.72$ years old) with no physical nor mental disabilities participated in the study (Table 1). The tests were conducted at Kuwait University Faculty of Medicine. Subjects ascended and descended the Faculty of Medicine, Kuwait University's five floors stairs (100 steps of $17.3 \mathrm{~cm}$ each, at $50 \%$ grade, total ascent of $17.3 \mathrm{~m}$ in 2 min, on average). Heart Rate and time elapsed were measured at every floor using Polar Watches. Energy expenditure was measured indirectly using a portable gas flow meter (Quark-b2) and gas analyzer (Cosmed, Rome, Italy) and expressed in $\mathrm{ml} \mathrm{O}_{2} \mathrm{Kg}^{-1} \cdot \mathrm{min}^{-1}$ or in metabolic equivalents $\left(1 \mathrm{MET}=3.5 \mathrm{ml} \mathrm{O} \mathrm{Kg}^{-1} \cdot \mathrm{min}^{-1}\right)$, at rest and at each floor. Blood Pressure was measured at the ground and fifth floors using a sphygmomanometer and auscultation. HRmax for each subject was estimated as: 220 minus age (years). Heart rate reserve (HRR) was estimated as HRmax-resting HR for each subject. Percent HRR $(\% \mathrm{HRR})$ was calculated as [(measured HR - resting HR)/HRR] $\times 100$.

\section{Results}

This stairs had $17.3 \mathrm{~cm} / \mathrm{step}, 50 \%$ grade and a total of 100 steps, but any stairs can be used as long as the height per step and the number of steps are known. The subject's descriptive anthropometric data are shown in Table 1. Females were shorter, lighter and had slightly higher HR max and rest HR than males. HRR was similar in F and M.

Table 1. Anthropometry and Heart rates (HR) in males and female subjects.

\begin{tabular}{ccc}
\hline Variable & Male (15) Mean \pm SD & Female (14) Mean \pm SD \\
\hline Age & $33.60 \pm 10.53$ & $30.93 \pm 10.69$ \\
Height & $1.72 \pm 0.05$ & $1.59 \pm 0.08$ \\
Weight & $82.27 \pm 13.04$ & $67.93 \pm 10.99$ \\
HR Rest & $74.33 \pm 7.18$ & $76.64 \pm 11.30$ \\
HR Max & $186.40 \pm 10.53$ & $189.07 \pm 10.69$ \\
HR Reserve & $112.07 \pm 11.62$ & $112.43 \pm 11.09$ \\
\hline
\end{tabular}


Subjects climbed at their chosen natural rate. Statistical comparisons of HR and METS, between male and female groups in ascending and descending stairs are shown in Table 2. The MET levels increased as subjects ascended the stairs but were lower and approximately constant during descent, F exhibiting higher METs than males at each floor during descent. Comparing MET used during ascent between floors, there were significant and gradual increases at all five stair levels up to 7.6 METs in F (Figure 1). In $\mathrm{M}$, the increases were significant at the first and second levels, smaller at the $3 \mathrm{rd}$ and 4th, reaching also 7.6 METs at the fifth floor (Figure 1). METs used at each elevation (m) are shown in Figure 2. The rate of ascent in F and $\mathrm{M}$ was similar and constant at each floor $(8.65 \mathrm{~m} / \mathrm{min})$ and is shown in Figure 3.

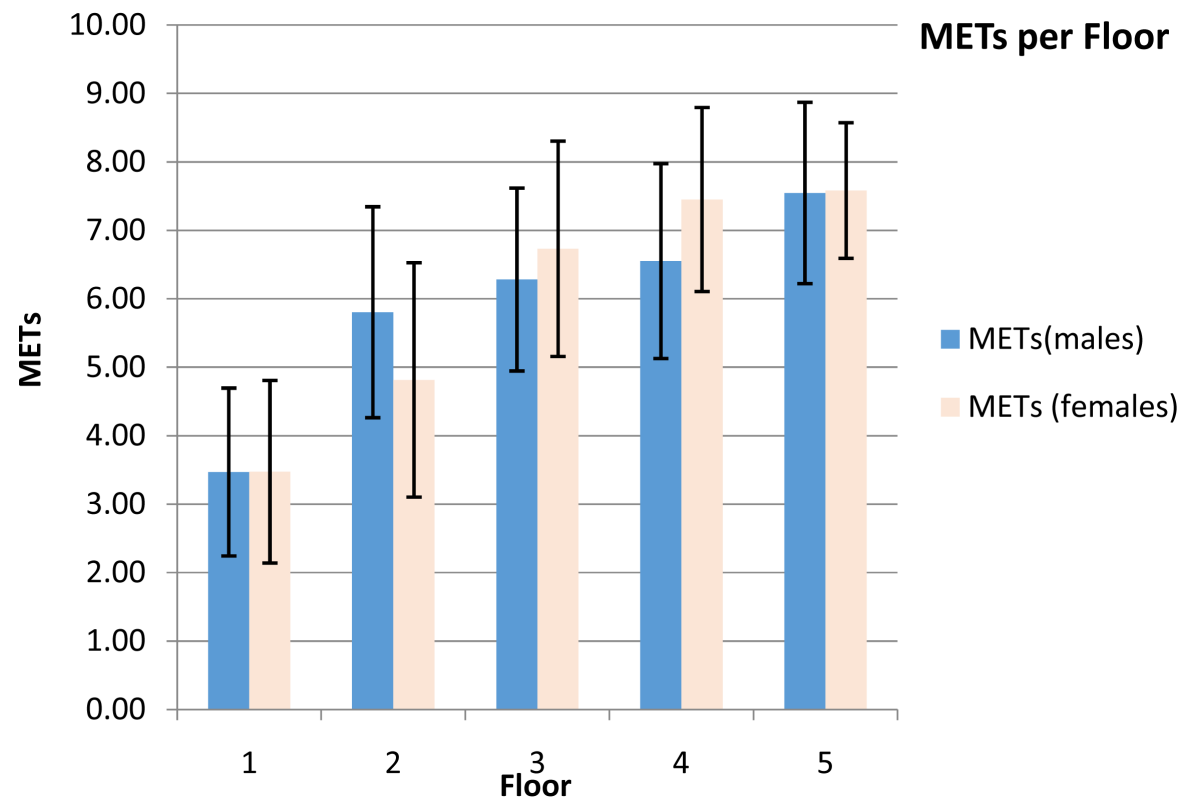

Figure 1. Energy cost (in Metabolic Equivalents (METs); 1 METs $=3.5 \mathrm{ml} \mathrm{O} \mathrm{Kg}^{-1} \cdot \mathrm{min}^{-1}$ ) of ascending 5 floors of stairs of 20 steps/floor, $0.173 \mathrm{~m} / \mathrm{step}$.

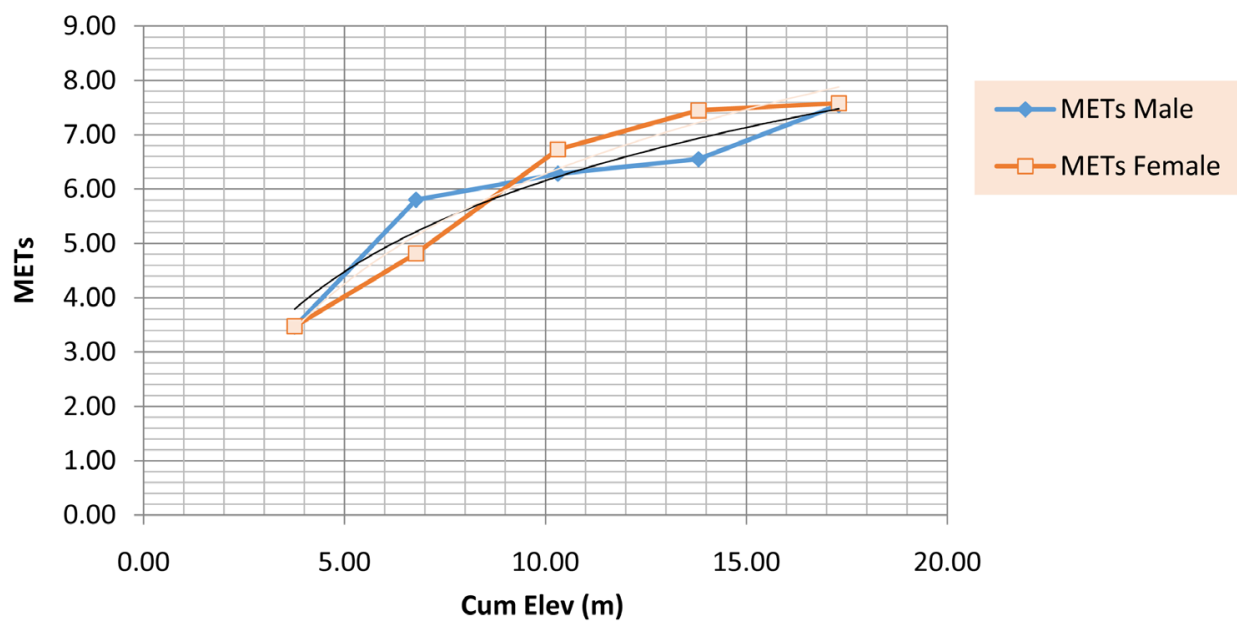

Figure 2. Energy expenditure while ascending a $17.3 \mathrm{~m}$ elevation stair in $2 \mathrm{~min}$. 
Table 2. Heart rates (HR) and energy costs (METs and $\mathrm{ml} \mathrm{O}_{2} / \mathrm{Kg}$.min) of males and females while ascending and descending 5 floors of stairs with 100 steps of $0.173 \mathrm{~m}$ each, in $2 \mathrm{~min}$ after $10 \mathrm{~min}$ rest.

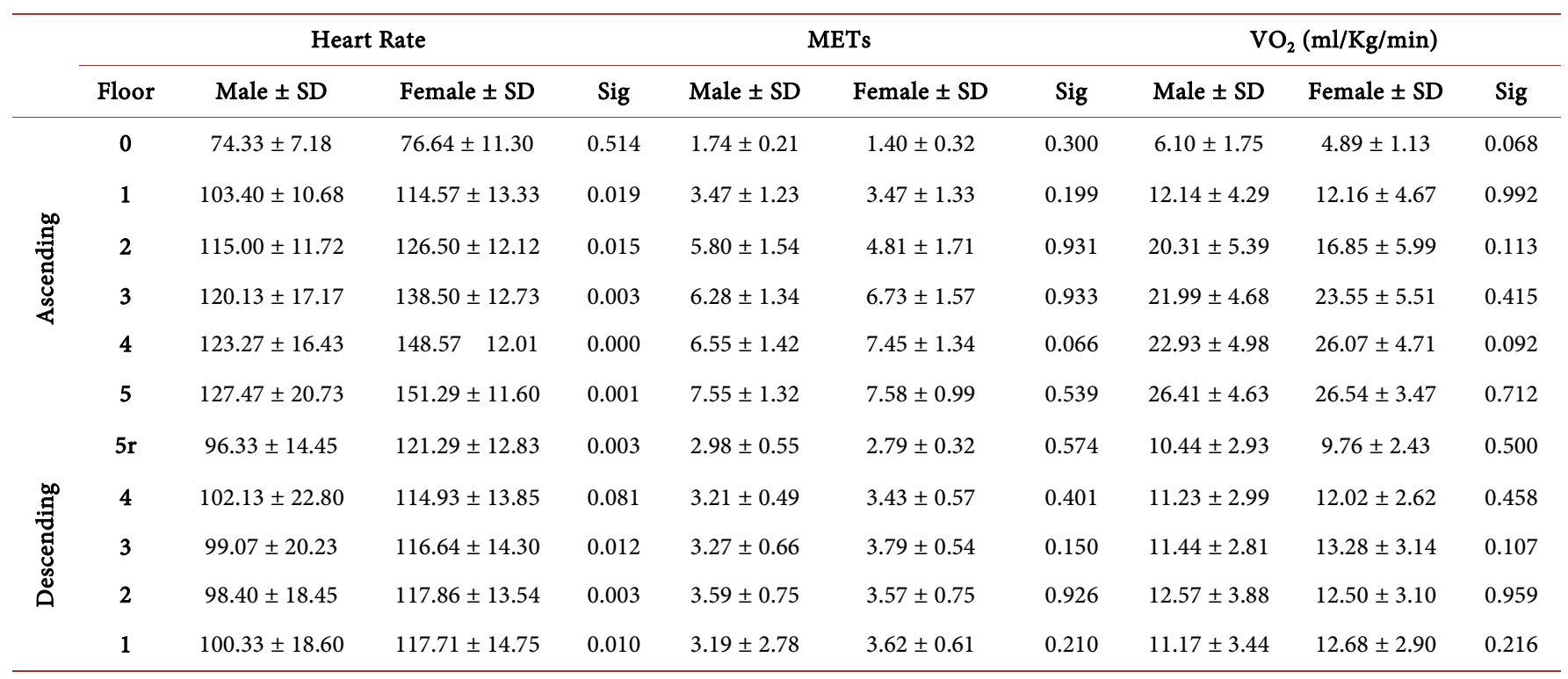

Cumalitive Time ( $\mathrm{min})$ taken to ascend 5 floors.

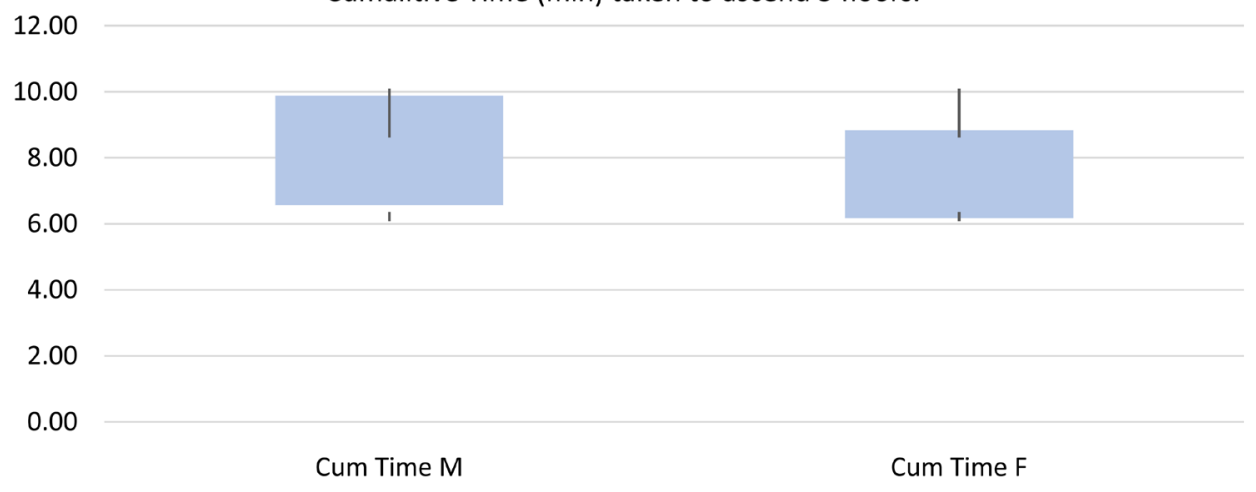

Figure 3. Time spent to ascend a $17.3 \mathrm{~m} 5$ floors stairs with 20 steps/floor.

No difference in resting HR were found between $F$ and M. HR were significantly higher after climbing each of the five stair levels in F than in M (Table 2, Figure 4(a)). The mean HR as percentage of estimated maximal at the end of each of five increasing stair levels were $55.7 \%, 61.9 \%, 64.8 \%, 66.6 \%$ and $68.8 \%$ in $\mathrm{M}$ and $60.6 \%, 66.9 \%, 73.2 \%$, $78.6 \%, 80.1 \%$ in F (Figure 4(b)). Figure 4(a) shows the relationship found between the average $\% \mathrm{HRR}$ and METs measured at each floor. The linear equations shown were the best fits found to the data.

The maximal METs that would be reached at $100 \% \mathrm{HRR}$, are calculated from the measured METs reached at the 5th level (7.6) divided by the fractional effort (derived from the \%HRR reached for $\mathrm{F}=0.6617$ and $\mathrm{M}=0.487$ ), at 11.48 METs for $\mathrm{F}$ and at 15.6 METs for M, similar to those derived from the indicated equations (Figure 4(a)). Maximal mechanical work output is estimated from the mechanical work at the 5th floor $(17.3 \mathrm{~m} \times 1 \mathrm{Kg} / 2 \mathrm{~min}$ ) divided by the measured fractional effort (from the \%HRR 


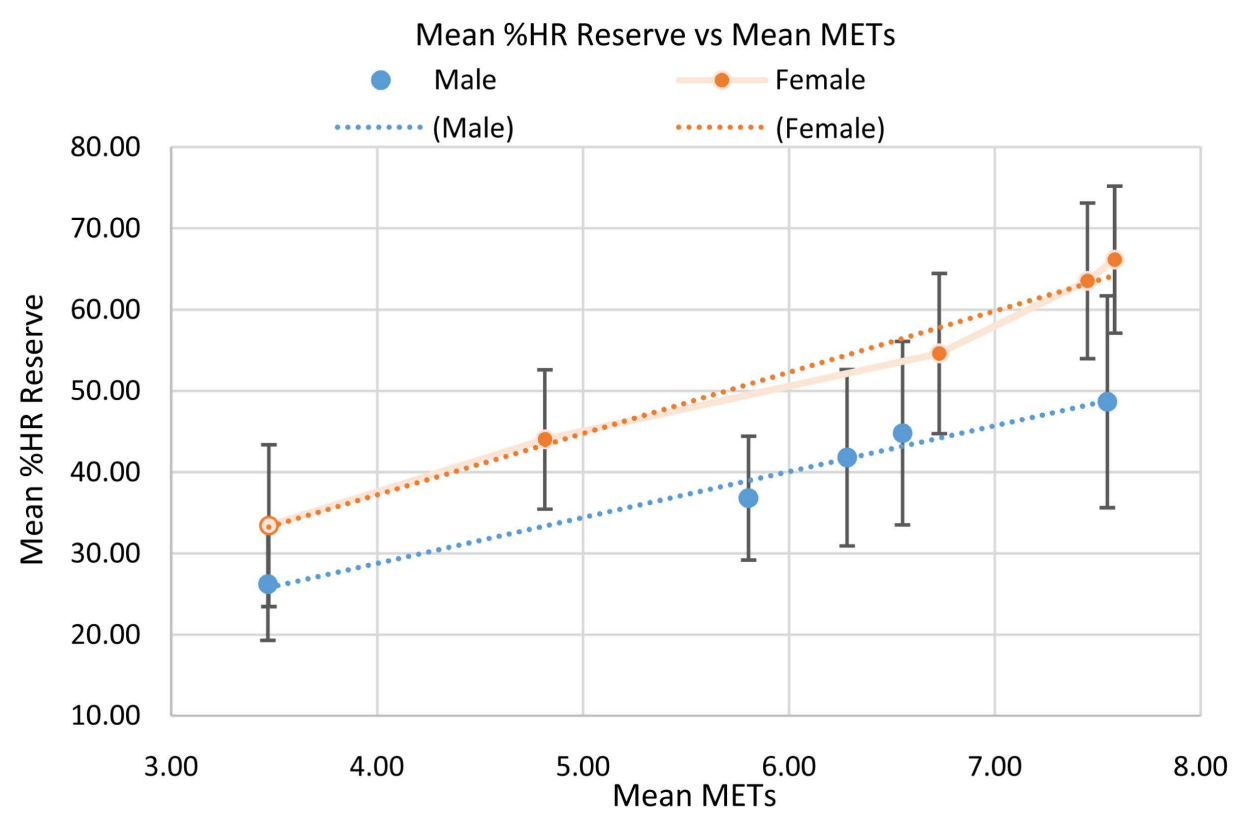

(a)

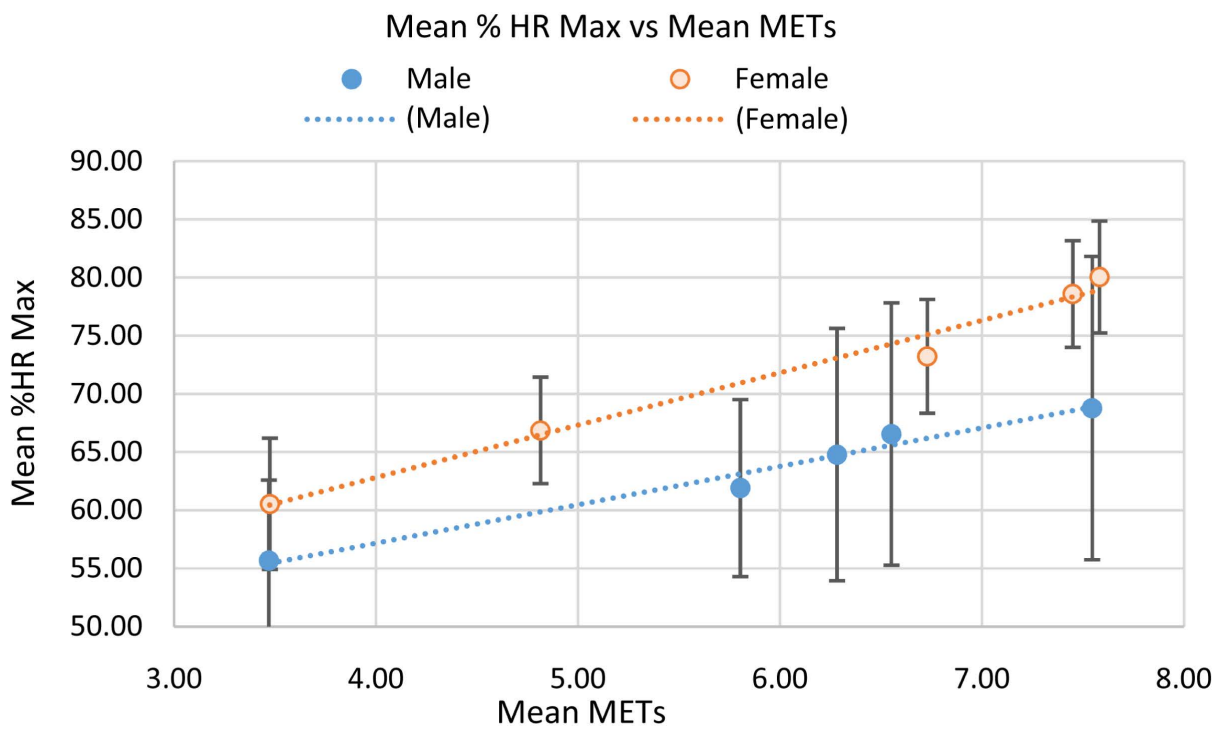

(b)

Figure 4. (a) Heart rate reserve reached at each level of energy expenditure (Mean METs) while ascending a 5 floor, $17.3 \mathrm{~m}$ stair; (b) Percent of maximal heat rate reached at each average level of energy expenditure while ascending a 5 floor stair.

reached F, 8.65/0.6617 $=12.98$ and $\mathrm{M}, 8.65 / 0.487=17.76 \mathrm{Kg} . \mathrm{m} / \mathrm{min}$ per $\mathrm{Kg}$ body weight lifted) which $(\times 0.00239$ to convert [3] $\mathrm{Kg} \cdot \mathrm{m} / \mathrm{min}$ to $\mathrm{Kcal} / \mathrm{min})$ are 0.031 and $0.042 \mathrm{Kcal} / \mathrm{Kg} \cdot \mathrm{min}$ in $\mathrm{F}$ and $\mathrm{M}$, respectively.

Efficiency of stair climbing for each subject $(n=29)$ is calculated dividing the measured highest rate of mechanical work output reached $(8.65 \mathrm{Kg} \cdot \mathrm{m} / \mathrm{min}$ per $\mathrm{Kg}$ body weight lifted $\times 0.00239=0.021 \mathrm{Kcal} / \mathrm{min}$ per $\mathrm{Kg}$ body weight lifted) by the measured highest rate of energy expenditure reached (on average $0.0266 \mathrm{~L} \mathrm{O}_{2} / \mathrm{Kg} \cdot \mathrm{min} \times 5 \mathrm{Kcal} / \mathrm{L}$ 
$\mathrm{O}_{2}=0.133 \mathrm{Kcal} / \mathrm{min} \cdot \mathrm{Kg}$ for both $\mathrm{F}$ and $\mathrm{M}$ ) yielding an average $\pm \mathrm{SE}$ of $0.158 \pm 0.023$ (fractional efficiency) or $15.8 \%$ for both $\mathrm{F}$ and $\mathrm{M}$.

Figure 5 shows the linear relationship found between \%HRR and $\%$ of $\mathrm{VO}_{2} \max$ (aerobic effort) in males and females indicating that \%HRR is directly proportional to the aerobic effort, in both sexes.

Aerobic capacity can be estimated, when oxygen uptake is not measured, from the calculated maximal rate of work output: 0.031 (for F) and 0.042 (for M) Kcal/Kg.min. Dividing by the measured fractional efficiency of stair climbing (0.158), gives estimates of the mean maximal rate of required energy input (expenditure) in Kcal/Kg.min: 0.197 (for F) and 0.269 (for M).These divided by $5 \mathrm{Kcal} / \mathrm{L} \mathrm{O}_{2}$ result in 0.039 (in $\mathrm{F}$ ) and 0.054 $\mathrm{L} / \mathrm{Kg} \cdot \min \left(\right.$ in $\mathrm{M}$ ) maximal $\mathrm{O}_{2}$ uptake, similar to those estimated by extrapolation of the data in Figure 4(a).

The average target training intensity in METs for females in this group, was estimated at 6.3 METS (Figure 4), using $60 \%$ of HRR, as the minimum recommended exercise training target [4]. Even if the energy costs are not measured, the elevation (m) at which $60 \%$ of HRR is reached can be easily determined. On average, females reached this training target slightly above the $3 \mathrm{~d}$ floor (10.3 m elevation) (Figure $4(\mathrm{a})$ ) but males on average, reached only $48.75 \%$ HRR at the 5 th floor (17.3 m elevation), indicating that their climbing rate $(8.65 \mathrm{~m} / \mathrm{min}$ ) should be faster (such as $10.6 \mathrm{~m} / \mathrm{min}$ ) if they want to use these stairs to reach $60 \% \mathrm{HRR}(9.6 \mathrm{MET}, 10.6 \mathrm{Kg} \cdot \mathrm{m} / \mathrm{min} \cdot \mathrm{Kg})$ for effective aerobic training. The \%HRR reached at the top, should be verified by direct measurement in each subject to insure that an adequate training intensity is achieved.

Systolic blood pressure increased to $140 \mathrm{mmHg}$ at the 5th floor in both males and females.

\%HR Reserve vs $\% \mathrm{VO}_{2}$ max

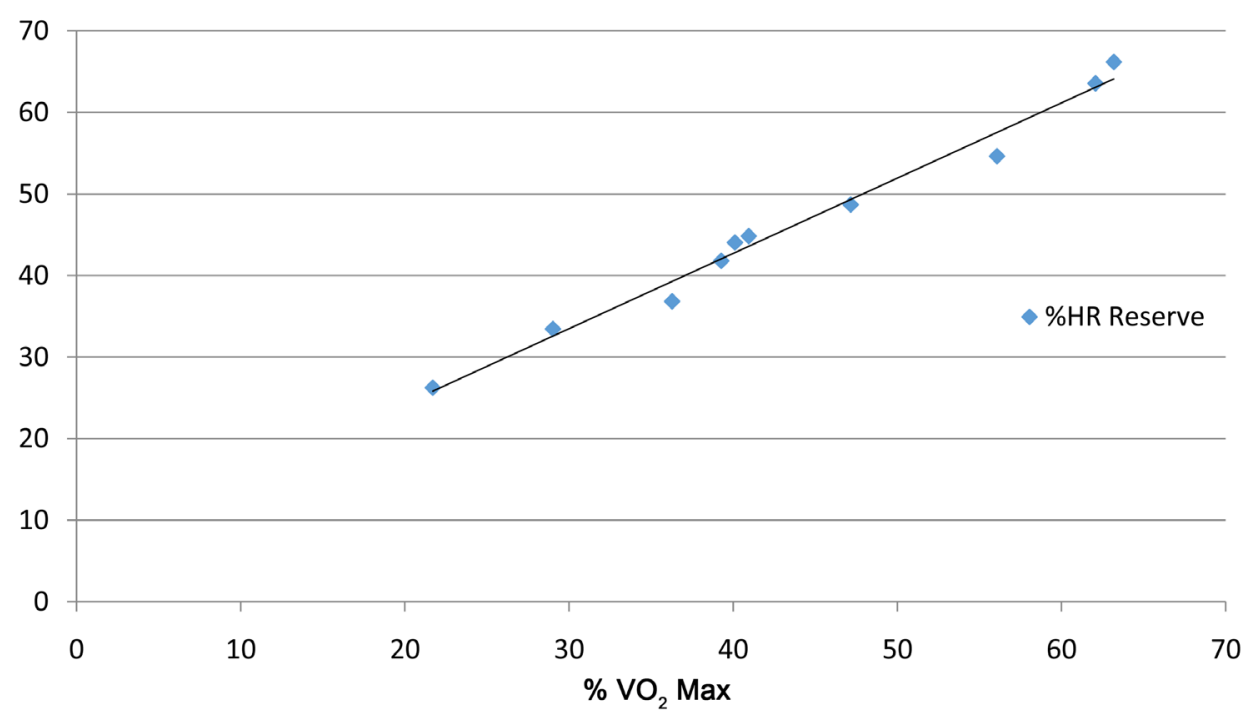

Figure 5. Relationship between percent aerobic effort $\left(\% \mathrm{Vo}_{2} \max \right)$ and $\%$ Heart rate reserve reached while ascending a $17.3 \mathrm{~m}, 5$ floor stair in $2 \mathrm{~min}$. 
During stairs descent the HR was 110 to 120 ; \%HRR was $15 \%$ and the METs used 2 to 3, in F higher than in M. F have higher HR after 10 min rest recovery than $\mathrm{M}$. By alternating ascents and descents the subject practices in addition to aerobic training, a form of interval training helpful to improve balance and flexibility.

\section{Discussion}

Health professionals may use stairs for submaximal evaluation of physical fitness (with estimate of MET max and aerobic capacity). This is readily done when HR and VO2 are directly measured (Figure 4(a)), by extrapolation to $100 \% \mathrm{HRR}$ and reading the corresponding $\mathrm{VO}_{2}$ from the derived equations (Figure 4(a)). When oxygen uptake is not measured, for each individual, aerobic capacity is estimated, from the highest rate of work output reached (in $\mathrm{Kg} \cdot \mathrm{m} / \mathrm{min}$ per $\mathrm{Kg}$ lifted, the corresponding fractional effort (from the highest \%HRR reached), converted $(\times 0.00239 \mathrm{Kcal} / \mathrm{Kg} . \mathrm{m})$ into Kcal $/ \mathrm{Kg} . \mathrm{min}$ and divided by the fractional efficiency of stair climbing ( 0.158 for these stairs), to estimate maximal energy expenditure in $\mathrm{Kcal} / \mathrm{min} . \mathrm{Kg}$, which when divided by the caloric equivalent of oxygen, $5 \mathrm{Kcal} / \mathrm{L} \mathrm{O}_{2}$ yields the maximal $\mathrm{L} / \mathrm{min} \mathrm{O}_{2}$ uptake per $\mathrm{Kg}$ body weight. The climbing efficiency changes little in stairs with different percent grades as the cost of horizontal displacement at each step depends on stepping rate but negligibly on horizontal displacement [5].

The rate of oxygen consumption reached after $2 \mathrm{~min}$ at the highest $(17.3 \mathrm{~m})$ level climbed by both $\mathrm{F}$ and $\mathrm{M}$ was $0.0266 \mathrm{~L} / \mathrm{min} \cdot \mathrm{Kg}(0.133 \mathrm{Kcal} / \mathrm{min} \cdot \mathrm{Kg}$ or $9.04 \mathrm{Kcal} / \mathrm{min}$ in F weighing $68 \mathrm{Kg}$ and $10.90 \mathrm{Kcal} / \mathrm{min}$ in $\mathrm{M}$ weighing on $82 \mathrm{Kg}$ ) which compared well with those in the manual of Bioenergetics for Exercise Sciences [5] and those previously reported in several studies $(7.8-13 \mathrm{Kcal} / \mathrm{min})$ evaluating the energy cost of stair climbing [6]. The Kcal used per min and per Kg lifted was independent of sex (0.133) and comparable with previously reported [6] stair climbing values $(0.110-0.185)$. In this study, we also used the measured highest attained work rate, the fractional effort (from the \%HRR reached, which we show in Figure 5 that is directly proportional to $\% \mathrm{VO}_{2} \mathrm{max}$ ) and the stair climbing fractional work efficiency (at $0.158 \pm 0.023$ in both males and females) to estimate the aerobic capacity of the subjects, since directly measuring oxygen uptake is rarely available to the healthcare worker. The Kcal spent per step was lower in females (0.18) than in males (0.219), given their lower body weight, and again within range of previously reported values (0.2) [7].

For patients with limitations, it is likely that they would reach efforts higher than $60 \%$ (as reflected by their \%HRR) at the 3rd floor compared to the healthy females in this study. Their stair climbing should be more limited (one or two floors). This can be assessed by monitoring their HR and not allowing it to reach more than $60 \%$ of HRR. Severely limited subjects may benefit by stair descents which require only 2 - 3 METs.

For exercise prescription, \%HRR is plotted against cumulated floor elevation (m). The elevation at which $60 \%$ of HRR is reached [4] is estimated, for example, at $10.3 \mathrm{~m}$ (the 3rd floor) for an average female in this study. For the healthy males, or athletes, the velocity of stair climbing may have to be adjusted so that at the top floor at least $60 \%$ of HRR is reached. 
Using a minimum recommended weekly physical activity volume of 600 MET.min per week for health maintenance [8], at an average exercise intensity of 6 METs, 100 $\mathrm{min} /$ week is the minimum total weekly duration of physical activity to be recommended for health maintenance. This can be broken down into sessions of about $20 \mathrm{~min} /$ day $(5$ ascents per day $\times 2 \mathrm{~min} /$ ascent $=10 \mathrm{~min}$ going up at $7.6 \mathrm{METs}=76 \mathrm{MET}$.min $/$ day and $10 \mathrm{~min}$ going down $\times 2 \mathrm{METs}=20 \mathrm{MET} . \mathrm{min} /$ day, for a total of $96 \mathrm{MET} . \mathrm{min} /$ day), 7 days/week frequency for a workout of $96 \times 7=672 \mathrm{MET}$.min/week, higher than previously suggested [9]. For health enhancing effects (to lower blood pressure, reduce cholesterol, weight loss, and enhance aerobic capacity) at least double the minimum physical activity volume recommended per week (at least 1200 MET.min/week) should be used and the subject retested after 3 months.

Elevations of systolic blood pressure during stair climbing much greater or smaller than $140 \mathrm{mmHg}$, decreases in diastolic blood pressures (DBP) or increases of DBP to values higher than at rest may indicate additional pathology.

Climbing stairs can thus safely be used as a mode of physical activity and exercise training by adjusting elevation (floors) climbed, the rate of climbing (time per floor) and the repetition rate while monitoring heart rate and timing. This can be used by healthcare providers or subjects that have no access to more sophisticated facilities.

\section{Funding}

By Department of Physiology, Faculty of Medicine, Kuwait University.

\section{References}

[1] World Health Organization (2014) Global Status Report on Noncommunicable Diseases. http://www.who.int/nmh/publications/ncd_report_full_en.pdf

[2] Lee, I.M., Shiroma, E.J., Lobelo, F., Puska, P., Blair, S.N. and Katzmarzyk, P.T. (2012) Lancet Physical Activity Series Working Group. Effect of Physical Inactivity on Major NonCommunicable Diseases Worldwide: An Analysis of Burden of Disease and Life Expectancy. The Lancet, 380, 219-229. http://dx.doi.org/10.1016/S0140-6736(12)61031-9

[3] Compendium of Physical Activities: Power Conversions (2011) https://sites.google.com/site/compendiumofphysicalactivities/help/unit-conversions

[4] Mann, T., Lamberts, R.P. and Lambert, M.I. (2013) Methods of Prescribing Relative Exercise Intensity: Physiological and Practical Considerations. Sports Medicine, 43, 613-625. http://dx.doi.org/10.1007/s40279-013-0045-x

[5] Kang, J. (2008) Bioenergetics Primer for Exercise Sciences. Human Kinetcs Ed., p. 76, Part 5, Fig. 5.5: Metabolic Equations for Various Activities. Bench Stepping.

[6] Halsey, L.G., Watkins, D.A.R. and Duggan, B.M. (2014) The Energy Expenditure of Stair Climbing One Step and Two Steps at a Time: Estimations from Measures of Heart Rate. PLoS One, 9, e100658.

[7] Plowman, S.A. and Smith, D. (2014) Physiology for Health Fitness and Performance. 4th Edition, Chapter 5, William and Wilkens Publishing, Lippincot, p. 127.

[8] Kaminsy, L.A. and Montoye, A.H.K. (2014) Physical Activity and Health. What Is the Best Dose? Journal of the American Heart Association, 3, e001430. 
[9] Boreham, C., Wallace, W. and Nevill, A. (2000) Training Effects of Accumulated Daily Stair-Climbing Exercise in Previously Sedentary Women. Preventive Medicine, 30, $277-$ 281.

\section{Submit or recommend next manuscript to SCIRP and we will provide best service} for you:

Accepting pre-submission inquiries through Email, Facebook, LinkedIn, Twitter, etc. A wide selection of journals (inclusive of 9 subjects, more than 200 journals)

Providing 24-hour high-quality service

User-friendly online submission system

Fair and swift peer-review system

Efficient typesetting and proofreading procedure

Display of the result of downloads and visits, as well as the number of cited articles

Maximum dissemination of your research work

Submit your manuscript at: http://papersubmission.scirp.org/

Or contact health@scirp.org 